\title{
Comparison of Mental Skills of Elite and Non-Elite Athletes
}

\author{
Sertaç Erciş \\ Correspondence: Sertaç Erciş, Faculty of Sport Sciences, Ataturk University, Erzurum, Turkey.
}

Received: May 29, 2018

doi:10.11114/jets.v6i4a.3425

\author{
Accepted: July 8, $2018 \quad$ Online Published: July 9, 2018
}

URL: https://doi.org/10.11114/jets.v6i4a.3425

\begin{abstract}
The main purpose of this reseach was to compare mental skills of elite and non-elite boys team athletes by Ottawa Questionnare. The reseach study was a descriptive-applied one. The data collection instrument was a questionnaire based on Ottawa questionnare that measured some mental skills factors. The subjects were 40 elite athletes and 40 nonelite athletes that they were randomaly taken up of basketball, volleyball, handball and futsall sport tournaments. $\mathrm{T}$ independent test was applied in order to analyze the related data to compare the results at $p<0.05$ level. The results indicated that the rate of Goal setting, self-confidence, Commitment, Stress reactions, Relaxation, Fear control, Activation, Focusing, Imagery, Competion planning, Mental practice and Refocusing skills is higher in elite athletic boy students in compare to non-elite ones.
\end{abstract}

Keywords: mental skills, elite, non-elite, team athletes

\section{Introduction}

Sport psychology has been established in many different advanced countries as a high potential establishment and is taught in many various universities as an independent field. Also most sport team champions apply this field as a great way of their readiness to reach to the psychiatric and mental readiness (Ozkan, 2015). Generally, achievement of sport skills depend on three readiness factors; physical, skill-based and mental issues. It seems that difference between the champions' performance is roughly relied on athletes' mental readiness; in addition, some research have shown that athletes with good mental readiness are more successful in tournaments achieving specified tasks in the framework of individual and team sports; these better mental skills let them to have high potential performance particularly at their self-confidence when they compete in tournaments.Also these athletes have better positive thinking power and decision-making in compare to other athletes; hence, the mental readiness can develop physical skills of athletes. Generally, the mental skills is a collection of techniques and methods that can be applied for expanding and developing athletes' sport performance, increase of concentration, develop of self-confidence particularly at their learning affairs (Cox, 2016). Although the context of the mental readiness plans is different in sport fields, it seems that the whole of these plans have got common topics such as goal setting, self-confidence, commitment, stress reactions, relaxation, fear control, activation, focusing, imagery, competion planning, mental practice and refocusing skills.

In the other hand, the perspective of athletes' mental readiness in various sport is different due to the features of its nature and type of skill; in other words, the optimized level of mental skills is different among sport fields. For example, Winter (2017) showed that the pattern of mental skills is not the same among wrestling, yachting and running athletes (Şahin, 2014). It seems that this difference exists between the individual and team sport athletes; it is obvious that the ignorance of these skills and the lack of accurate planning will lead to weaken the performance of the whole athletes in this regard. Hence, athletes should take their own physical and motor readiness at their own sport field. This will not be implemented unless the mental readiness of each sport field is gained by the same athletes. The present study has a great impact on the recognition of the elite athletes' mental readiness in the university atmosphere providing a pattern for the whole athletes in this pavement. This makes them to develop their mental readiness potentially at their various sport fields. Thus, the researcher is to evaluate whether the elite athletes' mental skills is significantly higher than non-elite athletes. Doğan (2011) concluded that the rate of motivation in controlling of mental imagery and their goal setting affairs is significantly higher than non-elite athletes. Şahin (2015) concluded that the degree of mental skills in elite athletes of is significantly higher than non-elite karate athletes. Cox (2016) concluded that the elite karate athletes have better imagery, goal setting, mental motivation, concentration, self confidence and adjustment of internal energy than ski athletes. Nasi (2011) in an evaluation of the impact of mental skills on the jumpers' performance in Finland athletes found that the mental readiness can influence on athlete's performance leading to the recovery of the same athlete during tournaments. 


\section{Method}

\subsection{Data Collection Instrument:}

The data collection instrument of the study is based on Ottawa questionnaire. It measures goal setting, self-confidence, commitment, stress reactions, relaxation, fear control, activation, focusing, imagery, competion planning, mental practice and refocusing skills of athletes.

\subsection{Statistical Community}

456 boys athletes in different sport fields (basketball, volleyball, handball and futsal) participated in sport tournaments during 2016-2017 by the number of team athlets. The statistical community of the elite athletes were selected based on the first to third ranking $(n=40)$ and the rest were selected as non-elite athletes $(n=40)$.

\subsection{Statistical Method}

$\mathrm{T}$ independent was applied to analyze data at $\mathrm{p}<0.05$ level using SPSS 21 software.

\subsection{Reliablity and Validity of Quastionnar}

The leading sport psychology questionnaire today is the Ottawa Mental Skills Assessment Tool version 3 (OMSAT-3) authored by Dr. John Salmela and his research team. The OMSAT is a valid sport psychology tool to assess the current mental strengths and weaknesses of athletes and other high achievers and design appropriate, training programs for performance improvement. The test was created to help researchers investigate the effectiveness of intervention programs to mentally train the mental skills of athletes of various skill levels, sports, and countries (Durand-Bush et al., 2001).

\section{Results}

Table 1. Comparison of goal setting, self-confidence, commitment, stress reactions, relaxation, fear control, activation, focusing, imagery, competion planning, mental practice and refocusing skills among elite and non-elite boy students

\begin{tabular}{|c|c|c|c|c|c|c|c|c|c|}
\hline \multirow[t]{2}{*}{ Dependent variable } & \multirow[t]{2}{*}{ Athlete } & \multirow[t]{2}{*}{$\mathrm{N}$} & \multirow[t]{2}{*}{$\mathrm{M}$} & \multirow[t]{2}{*}{ Dev. } & \multicolumn{2}{|c|}{ Levin test } & \multicolumn{3}{|c|}{$\mathrm{T}$ test } \\
\hline & & & & & $\mathrm{F}$ & Sig. & $\mathrm{T}$ & $\mathrm{df}$ & Sig. \\
\hline \multirow[t]{2}{*}{ goal setting } & Elite & 40 & 40.33 & 5.23 & \multirow[t]{2}{*}{1.961} & \multirow[t]{2}{*}{0.165} & \multirow[t]{2}{*}{4.211} & \multirow[t]{2}{*}{78} & \multirow[t]{2}{*}{0.001} \\
\hline & Non-elite & 40 & 35.03 & 6.00 & & & & & \\
\hline \multirow[t]{2}{*}{ commitment } & Elite & 40 & 41.65 & 5.61 & \multirow[t]{2}{*}{1.243} & \multirow[t]{2}{*}{0.268} & \multirow[t]{2}{*}{3.368} & \multirow[t]{2}{*}{78} & \multirow[t]{2}{*}{0.001} \\
\hline & Non-elite & 40 & 37.00 & 6.69 & & & & & \\
\hline \multirow{2}{*}{ Self confidence } & Elite & 40 & 42.43 & 5.05 & \multirow[t]{2}{*}{1.76} & \multirow[t]{2}{*}{0.188} & \multirow[t]{2}{*}{4.481} & \multirow[t]{2}{*}{78} & \multirow[t]{2}{*}{0.001} \\
\hline & Non-elite & 40 & 6.03 & 6.03 & & & & & \\
\hline \multirow[t]{2}{*}{ stress reactions } & Elite & 40 & 40.78 & 4.79 & \multirow[t]{2}{*}{0.065} & \multirow[t]{2}{*}{0.822} & \multirow[t]{2}{*}{8.358} & \multirow[t]{2}{*}{78} & 0.001 \\
\hline & Non-elite & 40 & 31.83 & 3.79 & & & & & \\
\hline Relaxation & Elite & 40 & 40.30 & 4.69 & 4.791 & 0.032 & 4.909 & 78 & 0.001 \\
\hline & Non-elite & 40 & 34.05 & 6.55 & & & & & \\
\hline Fear control & Elite & 40 & 44.28 & 5.79 & 0.061 & 0.722 & 6.350 & 78 & 0.001 \\
\hline & Non-elite & 40 & 32.72 & 4.34 & & & & & \\
\hline Activation & Elite & 40 & 40.18 & 4.79 & 0.044 & 0.822 & 8.358 & 78 & 0.001 \\
\hline & Non-elite & 40 & 31.55 & 3.99 & & & & & \\
\hline Focusing & Elite & 40 & 46.92 & 6.65 & 0.076 & 0.533 & 8.358 & 78 & 0.001 \\
\hline & Non-elite & 40 & 39.33 & 4.61 & & & & & \\
\hline Imagery & Elite & 40 & 42.25 & 3.90 & 2.809 & 0.098 & 5.440 & 78 & 0.001 \\
\hline & Non-elite & 40 & 35.50 & 6.13 & & & & & \\
\hline Goal setting & Elite & 40 & 40.33 & 5.23 & 1.961 & 0.165 & 4.211 & 78 & 0.001 \\
\hline & Non-elite & 40 & 35.03 & 6.00 & & & & & \\
\hline Competion & Elite & 40 & 45.88 & 4.79 & 0.063 & 0.643 & 7.358 & 78 & 0.001 \\
\hline planning & Non-elite & 40 & 30.48 & 3.34 & & & & & \\
\hline Mental practice & Elite & 40 & 49.28 & 6.70 & 0.037 & 0.421 & 5.676 & 78 & 0.001 \\
\hline & Elite & 40 & 31.44 & 5.19 & & & & & \\
\hline Refocusing & Elite & 40 & 39.78 & 5.67 & 0.076 & 0.677 & 6.496 & 78 & 0.001 \\
\hline & Elite & 40 & 34.78 & 4.46 & & & & & \\
\hline
\end{tabular}

According to the results of table 1, the rate of goal setting, self-confidence, commitment, stress reactions, relaxation, fear control, activation, focusing, imagery, competion planning, mental practice and refocusing in elite students is significantly higher than non-elite students.

\section{Discussion and Conclusion}

The results shoed the rate of goal setting, self-confidence, commitment, stress reactions, relaxation, fear control, activation, focusing, imagery, competion planning, mental practice and refocusing in elite students is significantly higher than non-elite students. 
The results of this research are coincident with the results of Cox (2016) and Adams (2013). Winter (2017) showed that the successful wrestlers have higher self confidence in compare to unsuccessful wrestlers. Also during the tournament, they are near to their high potential power concentrating only on their own wrestling events in this case. Ahola (1984) indicated that there is no significant difference between two groups of elite and non-elite athletes in terms of their physical and mental factors particularly at their mental skills. Adams (2013) also concluded that swimmers acting truly in this case have lower anxiety and higher concentration and self confidence along with high potential performanceal affairs at their sport field. Also they satisfy for participating in tournaments potentially. Ateş (2009) concluded that the elite lifters have higher and strong motivation than non-elite ones. Hug (1990) showed that the entire participants have a positive mental imagery, self confidence and goal setting and only the football team showed lower self confidence in this case. Bar, Hall and Rodgers (1990) concluded that the level of athletes' ability always does not have its own proportion and athletes using imagery issue may have been applied the process before the tournaments.Most athletes believed that the mental imagery process is very essential process during the tournaments. Golding and Wangerleader (20111) showed that the speed-runners, Marathon runners and skippers spend their times on mental imagery process. Myers et al (1993) concluded that the elite athletes are prior in two skills in compare to non-elite ones. Adams (1993) found the elite group had higher score than other non-elite ones in self confidence skill and motivation. Elite athletes had higher competence anxiety than the non-elite groups in anxiety.

Dong et al. (2014) observed that the elite athletes are prior in skills of mental imagery, motivation, controlling moods, self confidence and energy positively and significantly in compare to non-elite athletes. However in controlling the excitement the non-elite athletes were prior than elite ones.. White (1997) showed that the national team players had higher mental imagery in compare to the second group of the national team. Hallori et al (1997) found that the motivation is necessary to prevent any sport failures. They also figured out that the ball sports require higher motivation than tolerating and individual sports and the sport experience has a great impact on the sport progression. Tess and Huddleston (1999) found that the Chinese target, positive self speech and music can upgrade the athletes' psychiatric issues potentially. Myers and Borkioz (1999) found that the elite athletes had higher anxiety and concentration in compare to non-elite athletes.Also elite horse-riders did not show significant difference in motivation and self confidence skills but in mental readiness the elite athletes had higher level than non-elite ones. Bachanak (2001) found that young and adult boxers mental skills were normal in compare to other sport fields. Only successful boxers were different in seven interior factors of low or high intelligence, conservation, responsibility, simple person, and low self confidence and conservative with other athletes. Foolgham (2005) showed that the achievement of mental imagery and goal setting have significant impact on the effectiveness of coaches and the participants' self confidence. Marcus et al (2005) showed that the Brazilian footsal players had higher scores in relation to Chinese targets, self confidence and mental imagery while the Australian players were better in the variable of concentration. The worst score was related to both variable of mental practice. Nasi (2011) concluded that the mental readiness can influence athlete's performance and recovery during tournaments. Doğan (2011) compared some girl volleyball players in terms of their mental skills. The results of the research indicated that the elite players had higher scores in terms of concentration, self confidence, adjustment of energy level and mental imagery and Chinese goal setting but they did not have better motivation in this regard. Jaafari (2007) with the study of female taekwondo players' mental skills concluded that the lower motivation and higher concentration skills as well as mental imagery are higher only in elite people.

\section{References}

Adams, L., \& Smith, D. E. (2013) A Comparative analysis of cognitive difference among female elite and nonelite high school physical education class nonathletes. Montral. Canada.

Ahola, S. E. (1986). Psychological Momentum and competitive sport performance, perceptual and Motor Skills. N 63(3).

Ateş, M. J. (2009). The psychological skills Inventory for sport, Goleta. CA. Health Science Systems.

Cox, R. H., \& Liu, Z. H. (2016). Psychological skills of elite athletes, Journal of Sport Psychology, 27.

Doğan, F. (2011). Comparison of some mental skills of female volleyball players and non-elite ones, a thesis for MA. Teacher training college.

Dong, S. S., \& Kang, H. L. A. (2014). Comparative study of mental toughness between elite and nonelite female athletes. Korean Journal Sport science, 6(1), 224-228.

Durand-Bush, N., Salmela, J. H., \& Green-Demers, I. (2001). The Ottawa Mental Skills Assessment Tool (OMSAT-3*). The Sport Psychologist, 15, 1-19. https://doi.org/10.1123/tsp.15.1.1

Meyers, M. C., Bourgeois, A. E., Murray, N., \& Leunes, A. (1993). Comparison of psychological characteristics and skills of elite and sub-elite equestrian athletes. Medicine and Science in Sport and Exercise, 25. 
Ozkan, I. (2015). Comparison of mental skills perspective between elite and non-elite male karate players, MA thesis, Gazi University.

Şahin, A. (2014). Comparison of mental skills of elite players of participants in country's high school tournaments, a thesis for MA. Teacher training college of Tehran.

Winter, G., \& Martin, C. (2017). Basic training program, Third edition Adelaie. South Astralian Sport Institue (SASI). Sport Psychology Program.

\section{Copyrights}

Copyright for this article is retained by the author(s), with first publication rights granted to the journal.

This is an open-access article distributed under the terms and conditions of the Creative Commons Attribution license which permits unrestricted use, distribution, and reproduction in any medium, provided the original work is properly cited. 